\title{
EDUCAÇ̃̃O A DISTÂNCIA: UMA ABORDAGEM METODOLÓGICA E DIDÁTICA A PARTIR DOS AMBIENTES VIRTUAIS
}

RESUMO: Este artigo aborda a Educação a Distância a partir da influência dos ambientes virtuais. Suas exigências, suas relações técnico-pedagógicas necessárias e os pressupostos necessários aos processos ensino e aprendizagem a partir da utilização desses ambientes. A partir de uma análise do conceito de ambiente virtual e das implicações que sua influência impõe ao processo de ensino-aprendizagem, procura-se analisar algumas implicações metodológicas e didáticas aos projetos educacionais dessa natureza aplicados a essa modalidade de ensino a partir desses ambientes. Para isso, propõe-se uma reflexão sobre o conceito de Educação a Distância, a partir da compreensão dos domínios da educação, do professor e do aluno, tendo como fundamento os desafios que essa nova tecnologia apresenta a essa modalidade de ensino.

Palavras-Chave: Informática em Educação; Educação a Distância; Ambientes Virtuais.

\section{LONG DISTANCE EDUCATION:}

\section{A METHODOLOGICAL APPROACH OF TEACHING FROM VIRTUAL ENVIRONMENTS}

ABSTRACT: This article is about the influence of virtual environments in Long Distance Education: its demands, the techno-educational relations and the prior needs required in the process of education and learning that takes place in these environments. From an analysis of the virtual environment concept and the implications that its influence imposes to the teach-learning process, we analyze some methodology and didactic implications applied to this kind of educational project. So we propose a reflection on the concept of Long Distance Education, from the understanding of the domains of education, the teacher and the student, based upon the challenges that this new technology presents to this modality of education.

Keywords: Education in Long-Distance; Education; Virtual Education; Methodology of Education.

\footnotetext{
* Bacharel em Filosofia pela Universidade de São Paulo (USP); Pós-graduado em Informática em Educação pela Universidade Federal de Lavras (UFLA); Professor Palestrante em Educação, Tecnologias e EaD; Professor de Filosofia da rede pública e particular de ensino do Estado de São Paulo. E-mail: porfirioamarilla@gmail.com
} 


\section{Introdução}

As mudanças e os fenômenos ocasionados pelo processo de informatização intensificam o processo de globalização e atingem os diversos níveis da sociedade, produzindo várias alterações, desde os sistemas econômicos, comportamentos, modo de consumo até a percepção do mundo e da realidade e, principalmente, o modo de conhecer e aprender. A informática, enquanto conjunto tecnológico, tem sido causa de debates, análises, questionamentos sobre como operar essa tecnologia e como integrá-la aos processos educativos.

Este ensaio procura perceber como o processo educativo a distância se estabelece em suas relações metodológicas e didáticas diante das interferências dos ambientes virtuais. Por isso, quer percorrer o conceito de Educação a Distância, tendo como análise primeira a dicotomia física entre professor e aluno e os desafios ou dificuldades que os ambientes virtuais trazem a essa modalidade de ensino. Propõe, dentro das perspectivas de alguns desafios, uma análise das relações técnico-pedagógicas, a partir da compreensão de que não basta codificar um conjunto de saberes em ambientes virtuais para que se estabeleça uma relação pedagógica de ensino, mas que é necessário, também, estabelecer, sistematizar e organizar metodologias e didáticas específicas para a interação dos envolvidos no processo, a saber, professor e aluno.

Para isso, propõe uma reflexão sobre o papel do professor e do aluno diante dos novos desafios que se apresentam, assim como a percepção de que as metodologias e didáticas postas em prática nesses ambientes devem ser pensadas a partir de pressupostos metodológicos necessários. A intenção maior, portanto, é verificar algumas relações necessárias que, acredita-se, possam colaborar com o entendimento dos processos educativos da Educação a Distância, procurando fornecer algumas reflexões e alguns subsídios à sua compreensão a partir do uso de ambientes virtuais.

\section{Ambientes virtuais}

Com o desenvolvimento dos primeiros computadores na década de 1940, as tecnologias de informação e de comunicação passam a fazer 
parte não apenas do contexto científico e tecnológico, mas também ultrapassam outras instâncias da sociedade (AMARILLA, 2008). As mudanças e os fenômenos ocasionados pelo processo de informatização intensificam o processo de globalização e atingem os diversos níveis da sociedade, produzindo várias alterações: desde os sistemas econômicos voltados para o mercado até os comportamentos, o modo de consumo, a percepção do mundo e da realidade e, principalmente, o modo de conhecer e aprender.

O processo de digitalização de dados vem a ser um instrumento de criação para o desenvolvimento de um novo espaço de comunicação, organização, socialização, transformação e aquisição de conhecimento da sociedade (LÉVY, 1999, p. 32). A partir de suportes digitais como disquetes, disco rígidos, fitas magnéticas, CD-Roms, DVDs, etc. e a partir de suportes lógicos, como os aplicativos de criação de textos, imagens, sons; de sistematização de banco de dados, planilhas; de simulação, ambientes de apoio à decisão, cria-se um universo, um novo movimento sociocultural que invade as instâncias culturais, políticas e produtivas da ação humana.

Desse modo, foram criados sistemas, dispositivos interativos, redes, hipertextos, signos, ramificando um "hiperespaço" de informações universais que eclodiu nos anos 1990 como o "ciberespaço", em que os ambientes virtuais são as bases fundamentais para o acesso a esse novo universo.

Os ambientes virtuais postos em rede são interconectados e acessíveis a partir de qualquer computador conectado à rede, formando, assim, não apenas um conjunto de computadores conectados entre si, mas também viabilizando uma memória coletiva distributiva e distribuída, cuja definição ultrapassa a singularidade de um ponto qualquer disperso no espaço e no tempo e atinge a concepção de uma rede complexa. Complexidade essa que não se explica pelos limites nem pela disjunção das partes, senão pela própria unidade da qual essa mesma complexidade faz parte, em que o centro e a circunscrição dessa memória coletiva não podem ser delimitados por si mesmos, mas compreendidos pela sua unidade, dispersa e inacabada, sem limites, sem contornos.

Dessa perspectiva, a complexidade que atinge a rede de computadores surge também como memórias virtuais que ultrapassaram as funções técnicas, para operar o desenvolvimento de um conjunto de autono- 
mias individuais humanas, de participações comunitárias e do sentimento de pertencer a um tecnocosmo: o "ciberespaço".

Para Lévy (1999, p. 193), o ciberespaço forma a infraestrutura essencial, neste momento da história da humanidade, para exploração "dos recursos das capacidades humanas" por uma criatividade distribuída e incessante que não pode ser separada dos aspectos sociais e técnicos.

\section{0 ciberespaço, a nau, o timoneiro, o navegador e 0 capitão}

\footnotetext{
"Neste mar de conhecimento que a cibercultura traz à realidade, o professor assume o papel dos Argonautas que levam Jasão em busca do velo de ouro. No entanto, a nau que ele comanda não decide os rumos das aprendizagens, pois, o velo de ouro não esta em si mesmo na rota de sua nau, está na alma daqueles que o procura para navegar neste mar sem fim." (Porfirio Amarilla, inédito)
}

A metáfora citada acima não é sem propósito. O conceito de cibernética, usado por Weiner, tem origem no termo grego kyberentes, que significa "timoneiro", "leme", isto é, aquele que controla o curso da embarcação, preocupando-se com a manutenção da rota, de se preservar no rumo dos destinos traçados. No entanto, na hierarquia do navio, o timoneiro é apenas um cumpridor de ordens, não decide nem controla o curso da embarcação, controla apenas o navio. A cibernética, a partir dessa definição, designa controle e comunicação nos organismos ou nas máquinas (MACHADO, 1995, p. 234). Por extensão, o termo usado por Weiner passou a designar quaisquer sistemas mecânicos ou simuladores dos comportamentos complexos dos seres vivos (robôs, programas inteligentes, de autoaprendizagens ou capazes de adaptações, etc.).

$\mathrm{Na}$ gênese do primeiro computador, em 1946, o ENIAC, e do conceito de armazenamento de dados, em 1948, por Neumann, a informática e a cibernética se entrelaçam para compor o computador como um instrumento naturalmente cibernético e informacional. Desse modo, se, por um lado, a entrada e a saída de informação são transformadas em mensagens pela informática; por outro, é a máquina que controla e viabiliza o fluxo de informação acessível.

Com o advento das redes de comunicação informacionais, favorecidas pelo processo de digitalização, memorização e comunicação, o 
prefixo ciber recebeu nova extensão, a saber, espaço. O termo ciberespaço, usado pela primeira vez por Gibson em seu romance Neuromancer, em 1984, designa uma nova fronteira econômica e cultural, em que um universo de redes digitais se estrutura para operar e controlar o fluxo de informação. Para Lévy, o ciberespaço é "o espaço de comunicação aberto pela interconexão mundial dos computadores e das memórias dos computadores" (1999, p. 92), ou seja, uma das principais características é o acesso remoto aos diversos recursos em outro computador, formando, assim, um "mar" vastíssimo de informações acessíveis.

A figura do navegador surge como aquele que traça as rotas, que verifica os mares e os destinos que o timoneiro deve seguir. Portanto, é o navegador quem traçará os destinos e os objetivos da aventura, quem lê os mapas, calcula o tempo de viagem.

A metáfora se completa na figura do capitão, termo derivado do latim caput, aquele que comanda a nau, a cabeça de toda navegação, conhecedor não apenas da nau que comanda, mas também, pela experiência, dos mares navegáveis e dos portos. É quem possui a ciência, a razão, atento ao horizonte, aos ventos, favoráveis ou não, às tempestades, aos recifes, que mantém a ordem do navio. É aquele que "anima" a tripulação, que eleva o seu moral. Enfim, é o homem que põe prumo à navegação.

O mar, a nau, o timoneiro, o navegador e o capitão visam a demonstrar as relações necessárias à Educação a Distância quando se trata de compreender o papel de cada envolvido no processo educativo. O mar, o ciberespaço, torna-se o universo dos conhecimentos humanos postos de modo flutuante, esparramados, sem volume nem circunscritos. $\mathrm{O}$ timoneiro, a tecnologia, quem guia o navegador para o destino traçado, sua função é apenas de levá-lo ao destino desejado, de se manter na rota. A nau, os ambientes virtuais, que se limitam aos objetivos almejados e à eficácia da sua arquitetura para suportar os recursos propostos. E, por último, o navegador, o aluno, aquele que procura percorrer esse universo cujo destino é traçado por si mesmo, quem busca o saber; e, por fim, o capitão, o professor, aquele que dá conta do universo de conhecimento, do uso da tecnologia, dos ambientes virtuais e da orientação e animação do aluno ao saber, ao navegar. 


\section{Educação a Distância}

A análise a seguir procura entender o processo da Educação a Distância a partir de uma proposta fundamental para a construção do processo de formação do homem em seu contexto, a saber: a práxis.

Tem-se, por definição, que a educação navega por dois domínios: o primeiro, o prático-utilitário; o segundo, o humano, em que a autonomia é seu maior expoente. O primeiro visa a construir no homem um conjunto de saberes que lhe será útil no decorrer da sua existência, tornando-o apto a operar as dificuldades e as exigências que a sociedade lhe impõe. O segundo quer torná-lo capaz de exercer seu próprio domínio, de modo que reconheça em si a própria liberdade; que transcenda situações e opções de escolhas pessoais tendo em vista o outro, para que possa agir e pensar em conjunto com outros homens (SAVIANI, 2002, p. 37-38).

Desse modo, é papel da educação capacitar o homem não no sentido de apenas prepará-lo para uma existência e a sua preservação no ser, mas também no sentido de valorizar o humano diante de uma realidade concreta. A relação dialética que se estabelece a partir desses domínios tem dois elementos necessários: a realidade, enquanto o homem está situado em seu meio; e a capacidade do homem de pensar a própria realidade. Assim, tal homem se faz ser histórico, social e datado que perpassa por um contexto determinado, do qual e no qual ele produz seu modo de existir, ao mesmo tempo que produz seu conhecimento, suas relações sociais e seus valores culturais.

Segundo Paulo Freire, educar é um processo dialético entre o ensinar e o ser ensinado, em que "quem forma se forma e re-forma ao formar e quem é formado forma-se e forma ao ser formado" (1997, p. 25). Para ele, educar é compreender que, como ser histórico e posto no mundo, o educador faz parte do conhecimento, mas que também desconhece. Daí, pois, que "seja tão fundamental conhecer o conhecimento existente quanto saber que estamos abertos e aptos à produção do conhecimento que ainda não existe" (FREIRE, 1997, p. 31).

$\mathrm{Na}$ esteira do pensamento dialético marxista, Freire compreende que a realidade não é jamais apreendida de modo cristalizado, ela é conhecida por meio do processo de produção que engendra as ações humanas.

Dois movimentos de Marx estão na origem dessa compreensão; primeiro, a especificidade da existência humana, a práxis; segundo, a pos- 
sibilidade de o homem conhecer sua realidade objetiva. Se aquilo que é próprio da existência humana está caracterizado pela práxis, portanto, constituído pela necessidade e pelo trabalho, não há como tornar compreensível essa existência sem considerar a realidade objetiva do sujeito. A realidade objetiva, a partir da possibilidade de o homem conhecê-la, é que guia, além do processo de aprendizagem, também o processo de ensino.

Ora, se o processo de ensino-aprendizagem se constrói a partir da práxis, ou seja, em um sujeito histórico-social datado, e da possibilidade de o homem conhecer sua realidade objetiva, então, todo o esforço do homem em produzir meios de comunicação que vençam a distância como modo de operar sua realidade não pode ser negado ou negligenciado pela educação. Se as tecnologias de comunicação se inserem no contexto da existência humana e servem de suporte para a construção da realidade, como cartas, telégrafo, televisão, vídeos, computadores, etc., a educação, portanto, não pode abster-se de pensar, de promover e de utilizar tais tecnologias, desde que elas colaborem para aquele intuito primeiro, retomando, a promoção do homem no sentido de liberdade, autonomia e colaboração.

Contrapondo-se à educação depositária, Freire aponta para uma educação que liberte o homem por meio de reflexões e ações emancipadoras (PESCE, 2008). Assim, quando se fala em educação e, principalmente, em Educação a Distância, tem-se que a sua concepção se dá, também, a partir da compreensão de que é da realidade objetiva que os homens pensam os processos educativos. Tal movimento é fundamental à construção do processo ensino-aprendizagem com que a Educação a Distância se propõe colaborar, pois é desse movimento que a dicotomia física entre aluno e professor começa a ser pensada e vencida, integrando um e outro ao processo ensino-aprendizagem.

Educar a distância é, portanto, utilizar todos os recursos necessários de comunicação, metodológicos e didáticos para que o processo ensino-aprendizagem se realize sem a integração espacial e temporal síncrona entre aluno e professor, "a fim de refutar a mesmice reprodutora do modus vivendi" (PESCE, 2008).

Sob essa perspectiva, o sentido de "distância", dentro de um de processo de ensino-aprendizagem, pode ser entendido a partir de três relações: a distância entre professor-aluno, aluno-aluno, aluno-material (embora, cabe ressaltar, o termo "distância" tenha, dentro desse proces- 
so, uma definição relativa, pois a sensação de distância tem a mesma métrica que a distância espacial, isto é, um aluno, um professor, embora presente, pode estar mais distante dos seus pares do que aqueles ausentes). Todavia, o que dá sentido à Educação a Distância não é a dicotomia espacial e temporal, mas, ao contrário, sua capacidade de diminuir tal separação. O que dá sentido a tal processo não é o fato de Rondônia estar distante de São Paulo cerca de 3 mil quilômetros, mas o fato de que essa distância pode ser diminuída por meio de tecnologias, a favor do processo educativo, e aqui está a essência da Educação a Distância.

O fato é que a Educação a Distância implica uma dicotomia entre as tarefas dos processos de ensinar (estrutura organizacional, planejamento, concepção metodológica, produção de materiais) e dos processos de aprender (características e necessidades dos estudantes, modos e condições de estudos, níveis de motivação, etc.). Contudo, isso não significa que a Educação a Distância não possa diminuir as relações espaciais a favor do processo ensino-aprendizagem, ao contrário, definir o conceito de Educação a Distância e sua compreensão como modo de ensino é mais que defini-la como uma atividade de ensino e aprendizado sem que haja a proximidade física entre professor e aluno, aluno e aluno.

A Educação a Distância requer a compreensão de que é um processo de ensino-aprendizagem apontado para uma só dimensão: a proximidade do aluno, não no sentido espaço-temporal, mas no sentido do exercício da autonomia, da participação e da colaboração no processo ensinoaprendizagem. É o aluno motivado e "próximo" o foco principal de tal processo, a partir do conhecimento de suas características socioculturais, das suas experiências e demandas.

Desse modo, se, por um lado, é intuito da Educação a Distância integrar e possibilitar um conjunto de técnicas, metodologias, didáticas e meios de comunicação que promovam, a partir da realidade do aluno, a autonomia e a autoaprendizagem; por outro, é necessário que tenha como diretrizes e suporte a eficiência do ensino e a interação das relações alunoprofessor, aluno-aluno (PESCE, 2008, p, 33).

Todavia, percebe-se que há uma reconfiguração no modo de produzir e explicitar o conhecimento. O que se percebe, de fato, é que o termo "distância" se esgota em sua concepção a partir do que é a rede de computadores e o que é a cibercultura, que se forma ao redor dela. $\mathrm{Na}$ história da humanidade, pela primeira vez, qualquer indivíduo pode publi- 
car ou acessar qualquer informação ou dado, sob os mais diversos formatos e modulações, em tempo real e em qualquer espaço, adicionando ou abstraindo dali as próprias aprendizagens (LEMOS, 2007, p. 126).

Sob esse panorama, o termo "distância" perde seu valor conceitual de espaço e tempo tradicional para ganhar uma nova dimensão. Aqui, a Educação a Distância não pode ser comparada ou diferenciada pela sua relação espacial ou temporal, mas apenas pela dialética construtiva do conhecimento (ensinar-aprendendo e aprender-ensinando), que tem como fundamento a necessidade de existência e a necessidade de trabalho do homem. Dialética essa definida apenas pelos movimentos intrínsecos de conhecer, reconhecer/ensinar, aprender, que se estabelecem pelas possibilidades de produção e construção do conhecimento que a educação como um todo cria.

Desse modo, a Educação a Distância pode ser compreendida não apenas pela distância física entre professor e aluno, mas como um ensino aberto, flexível e formativo que se estabelece: a) por uma dicotomia temporal e espacial que pode ser superada pelas tecnologias humanas; b) visando à integração e à interação dos processos de ensino-aprendizagem por meio de processos metodológicos e didáticos específicos; c) por meio de alunos históricos, sociais e datados, que buscam o conhecimento a partir da própria leitura da realidade, tomando para si "conhecer" pelo meio de comunicação e processos que lhes convêm.

Definir ou comparar a Educação a Distância a partir de conceitos tradicionais de educação não revela a dialética construtiva do conhecimento (ensinar-aprendendo e aprender-ensinando). Dialética essa definida apenas pelos movimentos intrínsecos de conhecer, reconhecer/ensinar, aprender, que se estabelecem pelas possibilidades de produção e construção do conhecimento que a educação como um todo cria.

\section{Os desafios da Educação a Distância}

Não é intuito deste estudo esgotar todos os desafios, mas apenas trazer à reflexão alguns deles, ou seja, apenas refletir sobre alguns problemas que a interação tecnologia e educação apresenta à Educação a Distância.

Crê-se que os desafios para a Educação a Distância se colocam em três instâncias: i) no processo ensino-aprendizagem, enquanto escolha 
de recursos, planejamento e sistematização de metodologias e de didáticas; ii) no professor como profissional que exerce a ligação da primeira à última instância; e iii) no aluno como sujeito de toda ação da Educação a Distância

$\mathrm{Na}$ primeira instância, as tecnologias levantam diversas questões, mas talvez as mais emergentes sejam aquelas que se relacionam ao processo técnico-pedagógico. $\mathrm{Na}$ segunda, acredita-se que três elementos são fundamentais para a compreensão das dificuldades encontradas pelo professor.

Primeiro, entender a capacidade de produção, compreensão e gestão do conhecimento. Segundo, a compreensão do próprio papel do professor dentro do processo de ensino, da sua importância não apenas como mediador, facilitador, orientador do processo educativo, mas como animador e criador de possibilidades de aprendizagens. Por último, para o aluno, é a compreensão de que ele não faz mais parte de um modelo que recebe o conhecimento pronto, mastigado, orientado; mas que, em si mesmo, ele é o próprio construtor do seu conhecimento, cujo desafio é a percepção necessária da própria autonomia, da autodeterminação e da autodisciplina.

\subsection{Relação técnico-pedagógica}

Para Belloni (2006), no processo ensino-aprendizagem, a partir da inserção de ambientes virtuais na Educação a Distância, surge uma nova preocupação para as práticas educacionais: a necessidade de garantir dupla qualidade, a saber, pedagógica e técnica, quando se trata de ambientação virtual do ensino. À medida que as escolhas de ambientes virtuais (CDRom, salas virtuais, fóruns, e-mail, etc.) são feitas e passam a dar forma ao alcance da Educação a Distância, tais escolhas tornam essa modalidade de ensino muito mais dependente dos meios tecnológicos que o outro modelo de ensino. Isso implica um longo processo de preparação, planejamento, realização, pois, de fato, o que se espera é que os conteúdos sejam postos regularmente, assim como que as atividades, as respostas ou as avaliações cheguem a um tempo "curto", pois, este tempo é que influenciará o processo de ensino-aprendizagem (2006, p. 54). Os ambientes virtuais em que se pensa realizar um curso, uma aula, são coeficientes necessários para a gestão das condições de acesso e eficiência do processo pedagógico. 
Do ponto de vista pedagógico, o desafio está nas escolhas de ambientes virtuais que privilegiem não apenas a exposição de conteúdos, mas também a interação e a colaboração coletivas no processo de ensinoaprendizagem.

O ânimo que a Educação a Distância recebeu a partir do advento da rede de informação trouxe para essa modalidade de ensino o conceito de "comunidade cooperativa" do conhecimento, em que o conhecimento pode ser construído não apenas pela via professor-aluno, mas também pela via aluno-aluno e por uma memória coletiva mais acessível. Aqui, o que é privilegiado são as experiências dos próprios alunos em relação ao conhecimento desejado, a capacidade de interpretação de uma problemática, a interação entre a comunidade, a pesquisa que se desenvolve a partir de temas orientados pelo professor. Para Moran,

o conceito de comunidade de aprendizagem implica um deslocamento do professor e do conteúdo para o grupo, que participa, se envolve, pesquisa, interage, cria, com a mediação de algum orientador. Esta situação é nova seja no presencial como no virtual. É para ela que caminhamos em todos os níveis do ensino, porque supõe um avanço teórico e metodológico. (MORAN, 2007)

Nesse sentido, a comunidade cooperativa é o código genético do saber; é ela que tece o conjunto de cadeias genéticas do saber que, por meio da transcrição das mensagens de estímulos, operará e produzirá os "condões" do seu próprio conhecimento, em que o ciberespaço é "o suporte da inteligência coletiva, tanto em sua faceta coletiva como em seu aspecto social" (LÉVY, 1999, p. 207). O desafio que se tem é saber dosar uma pedagogia que foque a importância da leitura, da pesquisa e da compreensão do conteúdo, ao mesmo tempo que propicie a construção do conhecimento de modo colaborativo e comunitário em ambientes virtuais.

Do ponto de vista técnico, não basta codificar um conjunto de saberes em determinado ambiente virtual, é preciso ter em conta a acessibilidade técnica e a eficácia pedagógica. Além disso, é preciso ter em conta que é por meio do ambiente escolhido que se deverá planejar e delimitar o alcance do processo de ensino objetivado. Para Alava (2007), "a situação de ensino será, ela mesma, mediatizada pela interação recebida e construída entre a gestão da condução do ensino próprio ao aluno e a interação do dispositivo mediático nesta gestão". 
Cada uma daquelas tecnologias aplicadas exige do aluno e do professor comportamentos sociais e organizações específicas ao uso das potencialidades propostas. Por exemplo, um aluno, ao se reunir em uma sala de aula junto a outros alunos para assistir a uma videoaula coordenada por um tutor, requer um comportamento social do aluno diferenciado daquele que, em um quarto isolado, o aluno acessa salas virtuais. Aqui, a interação social se diferencia da outra modalidade, por isso, os modelos didático-pedagógicos têm de ser pensados também a partir dos modos de acesso tecnológicos.

O processo de ambientação virtual do ensino, tendo tais ambientes como ferramentas pedagógicas, cria um conjunto de ações com características próprias ao acesso e à leitura dos conteúdos, que requerem a gestão da ambientação para a condução do ensino ao aluno. Tal compreensão, no entanto, não encerra as questões técnico-pedagógicas em relação à Educação a Distância, ao contrário, à medida que se abrem soluções, abrem-se também novos desafios.

Contudo, o que se percebe de fato é que o dinamismo trazido pelos ambientes virtuais à Educação a Distância alimenta a necessidade de inovar e ponderar inovações a partir da relação técnico-pedagógica, invocando, ao mesmo tempo, o favorecimento de modelos eficientes de ensino-aprendizagem estruturados nas tecnologias, mas que não afasta, de modo algum, o pedagógico como elemento fundamental para a contribuição do sucesso do aluno (ALAVA, 2002, p. 247).

Em geral, na utilização de ambientes virtuais, percebem-se movimentos didáticos expositivos, depositários, em detrimento da interação e da colaboração do aluno à participação na construção do conhecimento. Fala-se muito em ambientes de aprendizagens virtuais, salas virtuais, videoaulas, programas de aprendizagens, entre outros. Todavia, a forma como esses ambientes têm sido operados não dá margem à participação efetiva do sujeito, o aluno, na organização e direção do aprendizado.

O salto que se deve dar para a viabilização da acessibilidade técnica e a eficácia pedagógica é a compreensão de um espaço físico estático (tradicional) para um espaço físico movente (revolucionário), caracterizado por um território informacional distinto do território físico do aluno, o que torna a aprendizagem rica em possibilidades. $\mathrm{O}$ uso de chats, fóruns, listas de discussão são apenas um dos diversos ambientes virtuais disponibilizados para o acesso. Hoje, até mesmo um telefone celular se torna ambiente privilegiado para a aprendizagem. 
É importante reforçar a ideia de que não se trata, portanto, de adaptação de uma pedagogia aos modelos de ensino presenciais, por meio de técnicas, à aplicação da Educação a Distância. Trata-se de perceber as tecnologias de informação e comunicação como parte de uma revolução científica que repercute como revolução tecnológica que perturba, modifica ou transforma o modo como o homem tem acesso ao conhecimento, à apreensão e representação da sua realidade, às relações sociais e como ele se vê e interage diante dessa mesma realidade (MORAN, 1999, p. 33).

\subsection{0 animador de aprendizagens}

Dispor as tecnologias da informática como meros instrumentos para manejo de algumas ações humanas (SETZER, 2001, p. 131) e dizer que sua compreensão encerra-se no domínio das ferramentas não colaboram para a reflexão sobre o papel do professor diante de ambientes virtuais, que exigem não apenas a compreensão utilitária dessas tecnologias, mas também a inteligibilidade de que tais tecnologias se inserem em um processo histórico do conhecimento humano.

Se antes se compunha como necessidade o professor ser mediador, facilitador, orientador, pesquisador de aprendizagens, hoje tais características não podem ser excluídas ao se pensar o que ele é. Em sua essência, o "ser" professor traz em si mesmo essas características. Não é possível concebê-lo sem que assim o seja, isto é, mediador, facilitador, orientador e pesquisador. No entanto, a inserção das tecnologias como um universo que comporta e promove o conhecimento, e invade as instâncias sociais como um modo de "expressão cultural", adianta-se sobre as suas habilidades e competências, exigindo dele modificações no modo de gerir o próprio conhecimento e o processo de ensino.

Por isso, o professor, dentro de um novo contexto, aqui entendido como "processual e histórico", vem a ser um animador do saber (LÉVY, 1999, p. 171). Naquele mesmo sentido usado por Aristóteles em De Anima, isto é, o professor como potência ativa de saberes (1999, p. 99), aquele que anima a mente do aluno ao conhecimento, à cultura, às aprendizagens, que cria possibilidades de aprendizagens e possibilidades à construção de um saber crítico diante dos desafios que a atualidade lhe apresenta. 
O "professor animador do saber" é aquele que se move junto com o aluno ao saber e à análise crítica do próprio saber. É aquele que sabe que é preciso se conhecer como humano. É aquele que não faz surgir respostas para os problemas, mas as problemáticas, suas relações, as interdependências, as totalidades. É aquele que se faz autônomo no saber, mas dependente da necessidade de saber "junto" com o outro; que faz crescer as incertezas sobre as instituições, os indivíduos e que provoca a si mesmo, interrogando-se sobre outras possibilidades. O professor animador revela ao aluno não o conhecido, mas aponta para o desconhecido.

Cabe ressaltar que a necessidade de "saber junto" amplia a potencialidade interativa entre professor-aluno e aluno-aluno, facilitada pela comunicação informacional, diminuindo a distância dos interlocutores. Contudo, não é suficiente apenas os ambientes virtuais para que se estabeleçam os processos comunicativos e interativos entre professoraluno e aluno-aluno. Antes, é necessário criar possibilidades que favoreçam a aprendizagem em sua totalidade, em que o diálogo seja multilateral e seja ânimo à "curiosidade" do aprender. O que se ressalta, aqui, na concepção do professor, é que ele seja sempre pertinente e relevante ao conhecimento apresentado, que seja organizado e promova a reflexão da aprendizagem e do conhecimento não apenas em si mesmo, mas também no aluno, a ponto de que possa também aprender com as experiências que cada um traz (MUT'TI, 2008).

Por isso, o professor, na sua formação, requer modelar-se pelo devir (como potência ativa em atualização), abrindo-se ao novo, ao incerto, ao risco. Não se dominando pelo "deixar vir", mas pelo ideal de uma educação que se revoluciona e requer a defesa de ideias emancipadoras, reflexivas e solidárias (PESCE, 2008).

Tais exigências solicitam do professor a aquisição de novos conhecimentos, novas habilidades e novos métodos de ensino. Sob essas condições, elas requerem um processo intenso de capacitação, fundamentado na motivação, na cooperação e na pesquisa, em que a utilização crítica da informação e das tecnologias, habilidades de pesquisa e comunicação são fundamentais para o exercício de ensinar, principalmente, para o professor da Educação a Distância.

Aquela afirmação de que o ensino por meio de ambientes virtuais é uma forma de atrair o aluno à aprendizagem, pois trata-se de uma novidade e motiva o aluno ao saber, esgotou-se. Ao contrário do que afir- 
ma Perrenoud (2000, p. 137), os ambientes virtuais não são concorrentes do professor. Não é por sua capacidade de produzir espetáculos de luzes e sons que eles se transformaram em modalidades de ensino, mas é por terem um propósito, procurarem expor os conhecimentos de modo rápido, simples e intuitivo.

O professor que se insere no universo do ensino por meio de ambientes virtuais tem de estar capacitado para lidar com as aprendizagens permanentes, para a orientação dos alunos em um espaço de saber flutuante, destotalizado, de aprendizagens cooperativas e comunitárias; capaz de gerir o conhecimento a si próprio e ao outro e, sobretudo, saber ensinar a autonomia para o conhecer e o pensar (LÉVY, 1999, p. 171).

Percebe-se, ao longo dos processos de ensino-aprendizagem implantados em ambientes virtuais, que há um deslocamento do centro que emana conhecimento para o que transmite conhecimento. Como foi dito antes, a relação técnico-pedagógica não pode se estabelecer tendo como princípio a nau; ao contrário, o capitão não pode apenas se deixar levar por ela. Ele a conduz em meio ao mar do conhecimento. Isso significa dizer que o centro que emana o conhecimento e cria possibilidades de aprendizagens, ampliando a dialética entre saber e aprender, está na perspectiva humana do professor. Segundo Almeida,

Ensinar em ambientes digitais e interativos de aprendizagem significa: organizar situações de aprendizagem, planejar e propor atividades; disponibilizar materiais de apoio com o uso de múltiplas mídias e linguagens; ter um professor que atue como mediador e orientador do aluno, procurando identificar suas representações de pensamento; fornecer informações relevantes, incentivar a busca de distintas fontes de informações e a realização de experimentações; provocar a reflexão sobre processos e produtos; favorecer a formalização de conceitos; propiciar a interaprendizagem e a aprendizagem significativa do aluno. (2008, p. 335)

É esse desafio que ergue a necessidade de o professor rever seu papel diante da Educação a Distância. Não se trata, portanto, de utilizar os ambientes virtuais a qualquer custo, trata-se de perceber o processo de transformação que ocorre incessantemente nas mentalidades, nas culturas e, sobretudo, no papel do professor e do aluno.

Segundo Moran (2007), não é apenas a tecnologia que resolve o distanciamento do aluno, mas a valorização da capacidade de se comuni- 
car, de gestos aproximadores e da gestão de processos participativos que movem o processo de ensino-aprendizagem diante dos ambientes virtuais. Ao professor, quanto maiores forem as diferentes situações que proporciona a si mesmo, melhor estará preparado para vivenciar diferentes papéis, metodologias e projetos pedagógicos (MORAN, 2005).

\subsection{0 sujeito do conhecimento}

Vygotsky procura explicar a significação dos fenômenos cognitivos a partir da natureza social e simbólica da atividade humana. Segundo ele, os processos de funcionamento mental, organizados culturalmente, são mediados por signos que apenas emergem na instância interindividual, em que a palavra, enquanto signo, e a mediação do outro caracterizam a atividade cognitiva (ARANTES, 2002).

As práticas culturais internalizadas implicam a construção e a reconstrução das formas de ação no plano intersubjetivo do indivíduo, permitindo uma configuração contínua das apreensões e interpretações dos contextos e, por isso mesmo, tal indivíduo aprende a organizar os próprios processos mentais e suas ações diante dessa organização que em si mesmo são elaboradas. Assim, mergulhado em um contexto cultural e participante das práticas sociais, historicamente constituídas, o indivíduo vai dando unidade às experiências. Portanto, em Vygotsky, é pelo outro que o indivíduo elabora as relações com os objetos de conhecimento. Desse modo, a relação cognitiva é fundamentada no outro, em que as ideias devem ser entendidas a partir da mediação da cultura e da interação entre indivíduos, ou seja, o meio é fonte de conhecimento e é condição para a constituição de si mesmo (PAIVA, 2002, p. 27).

Os sistemas de signos têm a função de construir e internalizar a cultura, daí, pois, a importância em se perceber o contexto cultural em que se encontra o aluno. Isso implica uma mudança de postura do professor, pois quer necessariamente um

repensar continuo da prática pedagógica no que se refere às relações existentes entre a aprendizagem escolar e desenvolvimento, à formação e desenvolvimento de conceitos, a importância da mediação na transmissão da cultura, ao papel dos conteúdos enquanto componentes do processo ensino-aprendizagem e no desenvolvimento do psiquismo humano. (PAIVA, 2002, p. 27) 
A rápida evolução do conhecimento exige de todos um permanente processo de aprendizagem individual. Dentro dessa perspectiva, aprender e conhecer apenas não basta, é preciso então saber conhecer, que implica saber lidar com a informação, separando aquilo que é relevante daquilo que é irrelevante. Disso resulta que a formação do estudante, diante dos processos de aprendizagem, deve ter como uma das prioridades a própria perspectiva de que nem ele nem os professores se encerram na formação que objetivaram ou objetivam para si. Tal processo, antes de tudo, é contínuo e nunca está verdadeiramente acabado.

Para o aluno, aprender é transformar as aprendizagens em conhecimento, o qual, por sua vez, deve ser socializado não apenas por meio de tarefas solicitadas, mas também com os pares. Aprender é estar sempre na posição de "descobridor", tomando para si aquela curiosidade em aprender, por entender, por apropriar-se da cultura que se modifica e que se apresenta agora. Aprender é visar a uma autonomia e independência. Por isso, é fundamental que o aluno renuncie ao papel de receptor. O aluno tem de se assumir como ser que observa o mundo e a si mesmo. Conhecedor dos seus afetos, possuidor de uma mente e uma afetividade que questionam os sentidos do mundo e sentem em si as provocações do mundo. $\mathrm{O}$ aluno hoje é aquele que busca ajuda, seja no ciberespaço, nos livros, nas discussões, no pensamento, seja no professor (ALARCÃO, 2003).

O desafio para o aluno, e também para Educação a Distância, é considerar essas características. Por um lado, elas são condições fundamentais ao sucesso do estudante. Por outro, é preciso uma pedagogia que oriente as finalidades da Educação a Distância para superar o enfoque tecnicista e que busque no conhecimento o processo de valoração humana, e não apenas pelo lado prático-utilitário. E, principalmente, que faça com que o aluno não se abandone à aprendizagem passiva, individualizada $\mathrm{e}$ solitária (BELLONI, 2006, p. 41-47). 


\section{Metodologia e didática em ambientes virtuais}

Pelo que foi posto até então, percebe-se que a Educação a Distância não apenas requer para si um conjunto de metodologias e didáticas comuns também ao ensino convencional, mas requer também inovação de uns, revisão de outros e o acréscimo de tantos outros.

Belloni (2006) menciona quatro áreas de competências, fundamentada na proposta de Blandin, em Formateur et formation multimédia, que apontam para uma reorientação da perspectiva metodológica e didática na Educação a Distância. São elas: i) cultura técnica, que exige domínio mínimo de técnicas de comunicação audiovisual e informática, os ambientes virtuais propriamente ditos; ii) comunicação, capacidade humana fundamental, não só porque a Educação a Distância requer, no seu exercício, a utilização e a difusão por meio de suportes comunicativos, mas porque a comunicação é a vela-mestra de todo processo de aproximação do aluno ao processo de ensino-aprendizagem; iii) metodologia e didática, que significa organizar situações de aprendizagem, planejar atividades, dispor de material de apoio, provocar reflexões constantes sobre os objetivos almejados, propiciar pesquisas e autoria de alunos e professores; iv) a tradução, que implica traduzir conhecimentos e experiências de modo que se possa aproveitá-los nos limites máximos dos objetivos circunscritos.

\subsection{Cultura técnica}

Em uma análise do primeiro ponto da proposta de Belloni, percebe-se que não basta apenas um conhecimento prático do uso dos ambientes virtuais. É preciso também estender esse domínio do ponto de vista pedagógico, ou seja, o que se espera para o desenvolvimento dessa competência é que ela favoreça as aprendizagens personalizadas e as aprendizagens coletivas. Tal dimensão abrange os muitos aspectos da relação técnico-pedagógica, que inclui a capacidade de seleção de ambientes virtuais, a elaboração de estratégias para o uso de tais ambientes, bem como uma noção dos melhores recursos desses ambientes à produção de materiais pedagógicos aplicados nesses meios.

Todavia, destacam-se dois movimentos, do ponto de vista pedagógico, que são fundamentais à abordagem desse estudo para o desenvolvimento dessa competência na Educação a Distância. Primeiro, não basta 
ter um corpo técnico que codifica, formata e processa o conteúdo pedagógico nem ter um professor treinado para operar os ambientes virtuais. É preciso direcionar os recursos técnicos para as áreas de conhecimento específicas que se visa a ensinar.

A utilização de ambientes virtuais na Educação a Distância requer a preparação de profissionais que possam implementar ambientes de ensino condizentes com as necessidades educacionais (ALMEIDA, 2003, p. 335), assim como a preparação de profissionais para implementar as necessidades educacionais nesses ambientes. Isso implica estruturar equipes interdisciplinares oriundas da educação, da comunicação e da ciência de computação que, juntas, devem pensar a gestão das condições de acesso e eficiência do processo pedagógico.

Por um lado, tal movimento implica um conjunto de conhecimentos necessários oriundo das ciências cognitivas, epistemológicas, psicológicas, sociológicas (BELLONI, 2006, p. 88), que se aplica à medida que se fazem essenciais ao processo ensino-aprendizagem, e não à medida que os recursos tecnológicos permitam. Por outro, implica ter um conjunto de conhecimento oriundo da ciência da computação que se aplica não pelos devaneios educacionais, mas pela eficiência em levar o processo de ensino-aprendizagem ao aluno por uma arquitetura informatiza prática, rápida e intuitiva.

A princípio, as teorias oriundas daquelas áreas do conhecimento humano que se somam ao processo educativo são apenas meio a serviço de uma finalidade (PERRENOUD, 2000, p. 48). Sua observação nesse processo não se estabelece, portanto, por meio de uma ditadura, contudo, elas apontam, de modo modular, para os mecanismos gerais de desenvolvimento dos processos de aprendizagem.

O que se reclama é exatamente que todo ferramental tecnológico, toda base de dados, toda arquitetura informatizada levem em conta e sejam de fato estruturados em relação aos objetivos do ensino, aos processos cognitivos, às motivações epistemológicas, às afetividades psicológicas e aos hábitos sociais, para que o aluno possa facultar para si a aprendizagem em conhecimento.

Segundo, trata-se da capacidade de decisão sobre o uso ou não de tecnologias, a aplicação ou não de propostas pedagógicas. Não se quer dizer, com isso, que se vise a impor limites à inserção das tecnologias nos processos educativos ou o contrário, o que se pretende é uma adesão crí- 
tica, pensada e elaborada a partir de uma proposta pedagógica, e não uma adesão acrítica dos ambientes virtuais àqueles processos, guiada pelo modismo ou por uma lógica de mercado.

O processo de decisão, portanto, não recai apenas sobre as tecnologias, cabendo somente a elas os sucessos e os fracassos dos métodos adotados, mas recai também sobre a pedagogia, em tirar maior e melhor proveito dessas tecnologias.

\subsection{Comunicação}

À medida que o processo de comunicação foi se tornando mais complexo e mais aberto no decorrer da história, as mudanças nos processos comunicativos da educação se tornaram, de modo evidente, mais emergentes para a compreensão do seu próprio contexto.

Os conceitos de comunicação, de presença, de continuidade se veem revistados com a inserção das tecnologias de comunicação. Essas tecnologias passaram a guiar uma nova percepção dos modelos de comunicação.

Moran (1998, p. 81) afirma que só vale a pena educar se for em um contexto comunicativo, participativo e interativo. Ainda, o que facilita o processo de ensino-aprendizagem, mais que a tecnologia, é a capacidade de comunicação que se estabelece nas relações educativas. Tal processo se vê, com o avanço dos meios tecnológicos de comunicação, envolvido também nos processos cooperativos, de pesquisas em grupo, de troca de experiências e de resultados, em que a dispersão geográfica dos interlocutores apenas afirma a necessidade de comunicação dos profissionais envolvidos na Educação a Distância.

Todavia, quando se pensa a utilização de ambientes virtuais, comunicar não é apenas transformar os conteúdos que se propõe ensinar em uma linguagem acessível, nem recolher resultados de aprendizagens daqueles que se ensinam. Comunicar é possibilitar ferramentas de comunicação que possam acompanhar o desenvolvimento do aluno, assim como incentivá-lo a resolver suas dúvidas, divulgar suas soluções, compartilhar suas divergências de pensamento e as próprias reflexões. A cada aluno e a cada professor envolvido no processo de ensino-aprendizagem são, eles mesmos, o "estar junto virtual, uma vez que atuar nesse ambiente significa expressar pensamentos, tomar decisões, dialogar, trocar infor- 
mações e experiências e produzir conhecimento" (ALMEIDA. 2003, p. 334).

Segundo Almeida (2008), a utilização de ambientes virtuais tem sua perspectiva favorecida pela possibilidade de interação e de construção colaborativa, pois favorece o desenvolvimento de competências e habilidades à elaboração e leitura do discurso em diversas linguagens (verbal e não-verbal, ao mesmo tempo, que promove a construção de ideias promovidas pelo debate.

A utilização de ambientes virtuais, portanto, deve ter como ênfase a possibilidade de comunicação proporcionada à Educação a Distância, pelo dinamismo de estabelecer processos comunicativos em várias formas de linguagem (escrita, oral e visual), de registro, memorização e recuperação de dados, não importando para isso o espaço e o tempo em que os interlocutores se estabeleçam. A comunicação por ambientes virtuais é a possibilidade, embora haja uma dispersão geográfica, de alunos e de professores alimentarem simultaneamente o processo de ensino-aprendizagem por uma memória compartilhada, coletiva e cooperativa.

\subsection{Metodologia}

A princípio, tem-se que o aluno da Educação a Distância deva possuir autonomia, autodisciplina e autodidatismo, que são atributos fundamentais para o processo de autoaprendizagem e sucesso do aluno em sua determinação. Separado fisicamente dos seus pares, dos seus professores, da sua instituição; o aluno da Educação a Distância, desse modo, exerce o monólogo interno do "conhecer". Isso significa dizer que tais atributos remetem o aluno à imagem do abandono, isto é, sozinho e isolado na tarefa de operar, sistematizar e apreender em si os caminhos do saber.

Aqui, tem-se uma questão fundamental para a Educação a Distância: o que significa de fato reverter o conceito de distância em proximidade?

À primeira vista, observa-se que todo processo de reversão do conceito de distância recai sobre a instituição, em que é ela quem organi$\mathrm{za}$, sistematiza e viabiliza os processos de ensino remotos, estabelecendo o modo de comunicação entre aluno-professor, aluno-material e alunoaluno, propiciando, assim, os ambientes de interações. 
Mas, embora a organização, a sistematização e a viabilização dos processos de ensino sejam fundamentais, a Educação a Distância não pode deixar de considerar em si mesma, como foi dito anteriormente, a necessidade de pensar e promover autonomia, autodisciplina e autodidatismo. No entanto, percebe-se que nem o modelo presencial nem o modelo a distância dão conta de que os alunos precisam ser preparados para a sua autonomia de aprendizagem, para a gestão do seu tempo e para o planejamento e direção do próprio aprendizado.

\subsubsection{Autonomia, autodisciplina e autodidatismo}

Belloni (2003) ressalta que o primeiro passo para uma metodologia de sucesso na Educação a Distância não é apenas a produção de materiais e processos avaliativos, mas também é superar a ausência de autonomia, autodisciplina e autodidatismo no aluno para que o conceito de distância se reverta em proximidade. Será que aluno egresso do modelo presencial, em particular da educação básica, traz em si esses atributos? O que é necessário para que as instituições que promovem a Educação a Distância estejam preparadas para lidar com alunos que não estão preparados para aquele abandono?

Crê-se que o primeiro movimento para suprir a ausência desses atributos no aluno é a conscientização do seu papel dentro da Educação a Distância, contribuindo para que ele se reconheça como sujeito da sua história e do processo de ensino-aprendizagem.

Segundo Moran (1998), o estímulo ao desejo de aprender, de ampliação das formas de percepção do conhecimento e, consequentemente, de comunicação tornam-se caminhos para ajudar o aluno a construir o processo da própria aprendizagem. $\mathrm{O}$ amadurecimento intelectual, emocional e comunicacional deve fazer parte do processo de organização das aprendizagens, visando a afastá-lo dos resultados prontos, da digestão de "conteúdo" a favor da pesquisa e da ampliação do próprio conhecimento (BELLONI, 2003).

Se a Educação a Distância, sob a égide de uma metodologia focada para esses ambientes, não propõe, nem estimula nem orienta à busca daquele conhecimento, no sentido de habilitar o aluno a filtrar, selecionar, comparar, avaliar, sintetizar e contextualizar os conhecimentos possíveis, a sensação de abandono se estabelece não apenas pela separação física dos ambientes das instituições e professores, mas também pela 
ausência de direção e motivação, caracterizando, desse modo, um ensino passivo, receptivo e solitário.

A possibilidade de interação que as tecnologias digitais propiciam à Educação a Distância propõe reorientações para um ensino compartilhado, participativo e comunitário, ou seja, implicam a possibilidade de se afirmar, em detrimento de um processo de ensino unilateral, depositário, autoritário, um ensino aberto, contínuo, não-linear (LÉVY, 1999), reorganizado de acordo com os objetivos ou com os contextos de cada um que se dispõe à própria formação.

A partir de ambientes virtuais é preciso compor uma metodologia que vise a despertar as afetividades positivas do aluno, para que ele vá além do "prato feito" dos materiais pré-produzidos; que incentive, oriente e proponha a auto-organização e que desperte a construção do próprio conhecimento. Como afirma Moran:

\footnotetext{
a grande inclusão que precisamos na educação não é a tecnológica - embora necessária - mas a afetiva e a de valores: Inclusão afetiva: acolher os alunos, valorizá-los, dar-lhes força, esperança, entusiasmo. Alunos motivados vão mais longe, caminham com mais autonomia. A afetividade é um componente fundamental pedagógico e contribui decisivamente para o sucesso pessoal e grupal. (MORAN, 2008)
}

Portanto, ao se dispor de ambientes virtuais como um meio do processo de ensino-aprendizagem, a Educação a Distância não pode considerar, a ponto de cometer um erro capital ao sucesso do aluno e à qualidade de ensino, aqueles atributos inerentes ao aluno. Ao contrário, deve utilizar tais ambientes também como um recurso para que aqueles atributos possam ser desenvolvidos ao longo do processo de ensino.

\subsubsection{Problematização}

O ensino não é um movimento de transmissão de saber que se encerra quando a mensagem é recebida, ao contrário, o saber deve ser fonte geradora, dialética, para um novo movimento do conhecimento. Daí, pois, que ensinar se torna a palavra-chave fundamental para a compreensão do próprio processo. Se, por um lado, ensinar remete ao conceito de pedagogia, isto é, em um sentido mais amplo, conduzir o aluno ao saber; por outro, ensinar também remete à didática, derivada do grego didaktika, que significa "relativo ao ensino", que se dá no interior do pro- 
cesso educativo (RIOS, 2001). Desse modo, o que se espera de um processo didático é que o ensino e a aprendizagem sejam intencionais, sistematizados e organizados, em que os conteúdos específicos possam ser propostos, explorados e avaliados ao correr de tal processo.

Se, de um lado, a inclusão das tecnologias no ensino requer uma racionalização dos processos educacionais que equacionem os processos pedagógicos de modo que se construam parâmetros e procedimentos mínimos a serem alcançados, tendo em vista gerar elementos auxiliares aos critérios de avaliação das aprendizagens do aluno; por outro, a ação de ensinar requer o contato e a interação para que se possa direcionar os objetivos de ensino centrado no aluno. Há, aqui, um ponto de tensão, a partir da racionalização de métodos e procedimentos, entre a proposta de um ensino que tem como base a realidade do aluno, isto é, que leve em conta os processos cognitivos, afetivos e culturais que em si mesmos foram desenvolvidos, com as características tecnicistas que os processos educativos a distância têm incorporado. Como operar as exigências de uma grade curricular engessada pelos "pacotes institucionais", os conteúdos pré-produzidos, as avaliações sistematizadas?

Com efeito, o saber não se constrói exclusivamente na relação instituição-aluno, em que o professor é um mero mediador entre um e outro. Se, por um lado, os alunos chegam com certa bagagem cultural ou quase nenhuma, cuja fonte são as próprias experiências e, como tais, não podem ser afastadas como parte das variações que revelam os caminhos para o êxito desses alunos (BOURDIEU, 1998); por outro, é na prática da responsabilidade e do comprometimento consigo mesmo (autodisciplina e autodeterminação), isto é, com a sua própria decisão de aprender, que cada aluno irá formar um conjunto de saberes individuais. A atividade do professor, como animador, então, é reconhecer o nível cultural do aluno, assim como, chamá-lo à cumplicidade do processo de ensino em que ambos estão envolvidos.

Dois elementos são necessários para explicitar o funcionamento dessa proposta didática, em particular, dessa cumplicidade que envolve a relação professor-aluno. Primeiro, o contrato didático estabelecido pela atividade recíproca e as posições de cada parte desse contrato. De um lado, o professor, cujo papel e intenção é ensinar, buscando sempre animar a curiosidade e a construção do saber; de outro, o aluno, que, animado pelo desejo de conhecer, supõe-se, aproxima-se desse mesmo saber 
por sua própria decisão. Segundo, a realidade do aluno, como parte extensiva de uma didática que procura observar e ampliar as respostas aos saberes que foram aplicados pelos processos de ensino-aprendizagem (FELIX, 2002).

Dentro desse panorama, a "atividade que visa à problematização dos conteúdos para a construção do conhecimento" pode ser percebida como a possibilidade de tornar mais visível o trabalho e o interesse pessoal do aluno nas suas dimensões mais objetivas, sem reduzi-lo apenas a parte integrante de um conjunto de procedimentos e objetivos metodológicos, incorporando gestos de estudos que não precisam ser vistos de um ponto normativo, mas como parte de ligações estreitas que ele mantém com a proposta de ensino e com os conhecimentos que nele lhe são construídos (FELIX, 2002).

Isso significa dizer que é da problematização que emerge o desconhecido. Conhecer é atividade em potência, problematizar é o conhecimento em ato. É a mente em seu movimento para exercer sua essência, isto é, pensando o conhecido para desvelar o desconhecido. A problematização surge, assim, como a possibilidade de uma observação continua do aluno em seus próprios espaços e tempos. Tal observação tem a função de atualizar e complementar o processo de construção do conhecimento no aluno. Como atenta Perrenoud (2000), a observação do aluno não se encerra na convivência em aula, ela se estende, de certo modo, para uma observação mais ampliada que compatibilize a gestão da classe, as atividades curriculares e extracurriculares; para que o professor interprete momentos que contribuam para estabelecer um quadro do aluno às voltas com as diversas tarefas propostas.

Se, por um lado, a problematização dos conteúdos visa ao professor facilitar uma análise da relação pessoal do aluno com o estudo, nos movimentos entre o ambiente virtual e o ambiente privado, no qual este último procura acumular para si as aplicações efetivas dos saberes construídos naquele outro ambiente; por outro, a produção ou a reprodução do conhecimento pode ser percebida pelo aluno em situações que não se encerram apenas no ambiente institucional de estudo, o privado pode também ser percebido por ele como o espaço que requer seu comprometimento e sua decisão em saber.

Desse modo, é aqui um dos pontos em que se sustenta o conceito de "construção cooperativa do conhecimento na Educação a 
Distância”. Ensinar, aprender, comunicar, unir, reunir, transformar, etc. podem ser compreendidos a partir do compartilhamento de uma busca que visa a dar sentido às problematizações. $O$ compartilhamento dos conhecimentos é construído a partir de referências e associações comuns entre os indivíduos que se conectam ao ambiente virtual, cujos valores cognitivos, sociais e culturais podem ser unificados ou não. Não obstante, esses conhecimentos se mostram como possibilidades de novas associações e novas criações em uma rede de colaboração, que depende intimamente do contexto em que aluno está inserido. Sob essa perspectiva, a problematização não pode ser pensada como uma estratégia temporária ou esporádica, mas deve ser pensada na Educação a Distância como elemento fundamental ao processo didático, em que é possível observar e analisar os caminhos que os alunos percorrem e o que podem fazer com o saber quando estão fora dos ambientes virtuais.

\subsection{Tradução de conteúdos}

A tradução de conteúdos de ensino em ambientes virtuais implica a percepção de duas instâncias necessárias: a primeira, o próprio processo de conversão de conteúdos em documentos digitais, que se instala como um processo de mediatização de conhecimentos apoiados sobre os ambientes virtuais e os formatos de documentação disponíveis ao acesso; a segunda, a especificidade didática que põe em jogo as relações de ensino capazes de apresentar os saberes e as experiências de modo que os alunos possam aproveitar e adequá-las em benefício próprio.

A primeira instância, segundo Alava (2007), apresenta como fundamento um modelo linear de comunicação, em que os ambientes virtuais se conectam à informação, desta ao aluno e deste ao saber.

(AMBIENTE VIRTUAL $\rightarrow$ INFORMAC̣ÃO $\rightarrow$ ALUNO $\rightarrow$ SABER)

O processo de tradução de conteúdos em ambientes virtuais é, a princípio, a elaboração de um processo de aprendizagem, todavia, ele não se estabelece apenas porque o aluno recebe informações que decodifica em saberes, mas também porque tal processo leva em conta conhecimentos preliminares, habilidades e competências pressupostas que se apoiam na organização cognitiva e na interação simbólica, como uma forma de 
tratamento não-linear das aprendizagens para cada envolvido no processo de ensino.

Aqui, a compreensão da segunda instância é fundamental, a saber, é preciso dar conta também, no processo de tradução, das especificidades didáticas que o conteúdo exige. Desse modo, o processo de ensino em ambientes virtuais é constituído entre a mediatização dos conhecimentos ao meio utilizado e pelas interações de saberes construídos pela gestão didática de tais conhecimentos disponível ao aluno.

Isso significa dizer que os processos de tradução de conteúdos em ambientes virtuais são, necessariamente, a inter-relação entre os meios digitais e os planos didáticos que se fundem para ser instrumento pedagógico (ALAVA, 2007). Aqui, o plano de tradução é indissociável do plano didático e, por isso, o primeiro deve ser compreendido e elaborado não pela linearidade dos modelos comunicativos, mas, ao contrário, pelas derivações que o processo de ensino-aprendizagem apresentam. Isso significa ter como pressuposto que o processo de aprendizagem também é conduzido pelo próprio aluno e se vê levado a pensar a diversidade dos alunos, das formas de abordagem de conteúdos e das relações estabelecidas entre esses alunos e destes com o conhecimento.

Daí, pois, que a tradução de conteúdos para os ambientes virtuais não pode estar centrada apenas na exposição sumária, mas, no sentido contrário, na problematização, em que o foco do plano didático está na sua capacidade de gerar problemas para que aluno percorra as próprias descobertas. Segundo Moran (2005),

o foco na aprendizagem será predominante. A aprendizagem (será) realizada não pela "decoreba", mas sim pela participação em projetos organizados em torno de problemas e que levem a "descobertas" pelos alunos de conhecimentos novos. Busca-se mais o equilíbrio entre a aquisição de competências necessárias para sobrevivência no mundo moderno (identificar problemas, achar informação, filtrar informação, tomar decisões, comunicar com eficácia) e a compreensão profunda de certos domínios de conhecimento estudados. (MORAN, 2005)

A tradução deve levar em conta a cognição do aluno como uma prática inventiva e autônoma, em que problemas, erros e avaliação não são apenas instâncias passíveis de escolhas à aplicação de conteúdos em ambientes virtuais, mas são partes inerentes ao processo de ensino-apren- 
dizagem que se visa a gerenciar. Ela não é apenas uma forma de codificação de conteúdo para a aprendizagem, antes, ela é o efeito de um processo de ensino-aprendizagem pensado para criar e valorizar as possibilidades de aprendizagens mais dinâmicas, interativas e participativas.

\section{Considerações finais}

Ao logo deste estudo, buscou-se compreender por que a Educação a Distância exige uma pedagogia que não se deixe seduzir apenas pelo enfoque técnico, mas que tenha também uma preocupação com as relações metodológicas e didáticas. A Educação a Distância, em que se faz uso de ambientes virtuais, requer a compreensão de que os elementos comunicativos, temporais e espaciais são assíncronos e, portanto, requer a concepção de metodologias e didáticas que orientem o aluno para autonomia, autodisciplina e autodidatismo, assim como, para o professor, a percepção de uma mudança significativa no modo da compreensão o seu papel.

Ao primeiro, a gestão do processo aprendizagem se insere em uma exigência que deve abandonar a postura passiva, receptiva e dependente. É fundamental que ele se assuma como construtor do próprio processo de conhecimento. Ao segundo, é fundamental que ele compreenda o processo de ensino, a partir de ambientes virtuais, como um universo que exige a disposição para o aprender junto, em que utilizar novos modelos comunicativos, aplicar metodologias e didáticas construídas a partir do conceito das comunidades cooperativas se tornam exigências emergentes nesse processo.

A inserção de ambientes virtuais no processo de ensino poderá levar a reflexão sobre a educação a outro nível de discussão. Desde aquelas que se referem às etapas de formação dos professores, o que implica inseri-los nesse contexto informacional e comunicativo que se adianta aos processos formativos, até aquelas que pensam e debatem as instâncias tecnológicas não apenas como elementos instrumentais para a educação, mas também como elemento cultural do homem contemporâneo.

Uma educação para a liberdade e emancipadora requer a percepção de que as mudanças de paradigma não ocorrem apenas na perspectiva de uma educação inovadora, mas também na percepção de que, em si 
mesma, a educação é fruto, essencialmente, dos movimentos que ocorrem no domínio humano, isto é, da percepção da existência em si mesma como capacidade humana para gerar mudanças e transformações.

Educação em Revista | Belo Horizonte | v.27 | n.02 | p.41-72 | ago. 2011 


\section{REFERÊNCIAS}

ALARCÃO, Isabel. Professores reflexivos e escola reflexiva. São Paulo: Cortez, 2003. Cap. 1, 2 e 4 .

ALAVA, Seraphim. La formation médiatisée: dérives et enjeux. Disponível em $<$ http://pagesperso-orange.fr/alava/TIC2002/AlavagiratV2.htm>. Acesso em 14/03/2007.

ALAVA, Seraphim. L’université, entre l'immobilisme et le renouveau. Revue des sciences de l'éducation, Canadá, v. XXVII, n. 2, p. 243-256, 2001.

AMARILLA, Porfírio. Educação e a cultura da informática. Revista Eletrônica de Educação. UFSCAR, 2008. Disponível em <http://www.reveduc.ufscar.br>. Acesso em 16/03/2008.

ALMEIDA, Maria E. B. de. Educação a distância na Internet: abordagens e contribuições dos ambientes digitais de aprendizagem. Educação e Pesquisa, São Paulo, v. 29, n. 2, p. 327-340, jul./dez. 2003.

ARANTES, Valéria A. Afetividade e Cognição: Rompendo a Dicotomia na educação In: OLIVEIRA, M. K; TRENTO, D.; REGO, T. (Orgs). Psicologia, Educação e as temáticas da vida contemporânea. São Paulo: Moderna, 2002. Disponível em <http://www.hottopos.com/videtur23/valeria.htm>. Acesso em 17/10/2007.

ARISTOTELES. De anima. Campinas: Unicamp/IFCH, n. 38, setembro/1999. ARISTOTELES. Política. São Paulo: Martin Claret, 2006.

BELLONI, Maria L. Educação à Distância. Campinas: Autores Associados, 2006. BOURDIEU, Pierre. O poder simbólico. Rio de Janeiro: Bertrand Brasil, 2000.

BOURDIEU, Pierre. A escola conservadora: as desigualdades frente à escola e à cultura. In: Nogueira, M.A., CATANI, A. M. (Orgs.). Escritos de Educação. Petrópolis: Vozes, 1998. p. 41-64.

FÉLIX, Christine. L'etude à la Maison un système didactique auxiliaire. Revue des sciences de l'éducation, v. XXVIII, n. 3, p. 483-505, 2002. Disponível em

<http://www.erudit.org/revue/rse/index.html>. Acesso em 12/03/2008.

FREIRE, Paulo. Pedagogia da autonomia: saberes necessários à prática educativa. 2 ed. São Paulo: Paz e Terra, 1997.

LEMOS, André. Cidade e mobilidade. Telefones, celulares, funções pós-massivas e territórios informacionais. Matrizes / Revista do Programa de pós-graduação em Ciências da Comunicação da Universidade de São Paulo, São Paulo, Ano I, n. 1, jul-dez 2007.

LÉVY, Pierre. As tecnologias da inteligência. Rio de Janeiro: 34, 1993.

LÉVY, Pierre. O que é virtual? Rio de Janeiro: 34, 1996.

LÉVY, Pierre. Cibercultura. Rio de Janeiro: 34, 1999.

MACHADO, Nilson J. Epistemologia e didática - as concepções de conhecimento e inteligência e a prática docente. São Paulo: Cortez, 1995.

MORAN, J. M. A aprendizagem de ser educador. Dez 2007. Disponível em

$<$ http://www.eca.usp.br/prof/moran/aprend.htm>. Acessado em 31/03/2008.

MORAN, J. M. Educação afetiva ou controladora? Foco no conteúdo ou em valores? Disponível em <http://www.eca.usp.br/prof/moran/controladora.htm>. Acessado em 25/05/2008a.

MORAN, J. M. Tendências da educação on-line no Brasil In: RICARDO, Eleonora Jorge

Educação em Revista | Belo Horizonte | v.27 | n.02 | p.41-72 | ago. 2011 
(Org.). Educação Corporativa e Educação a Distância. Rio de Janeiro: Editora Qualitymark, 2005.

MORAN, J. M. Mudar a forma de aprender e ensinar com a Internet. In: Salto para o futuro: Tv e Informática na Educação. Brasília: MEC, SEED, 1998.

MORAN, J. M. Os modelos educacionais na aprendizagem on-line. Disponível em http://www.eca.usp.br/prof/moran/modelos.htm>. Acessado em 17/03/2008b.

MUT'TI, Regina M. Varini; AXT, Margarete. Para uma posição enunciativa no discurso pedagógico mediado por ambientes virtuais de aprendizagem. Interface (Botucatu), v. 12, n. 25, p. 347-361, jun. 2008.

PAIVA, Carlos Roberto. Avaliação de software educativo "bistória do mundo, uma aventura visual”: aplicações no ensino presencial de história. Dissertação (Mestrado). UFSC. 2002. Disponível em <http://teses.eps.ufsc.br/defesa/pdf/9235.pdf>. Acessado em 16/10/2007.

PERRENOUD, Philippe. Dez novas competências para ensinar. Porto Alegre: Artmed, 2000. PESCE, Lucila. Educação a Distância e formação de educadores: a contribuição dos desenhos didáticos dialógicos. 31 $1^{\mathrm{a}}$ REUNIÃO ANUAL DA ANPED. Disponível em < http://www.anped.org.br/reunioes/30ra/index.html>. Acessado em 4/1/2010.

SETZER, Valdemar W. Meios eletrônicos - uma visão alternativa. São Paulo: Escrituras, 2001.

\author{
Recebido: $18 / 08 / 2008$ \\ Aprovado: 21/03/2011 \\ Contato: \\ Rua Djalma Pessolato, 186 \\ CEP 04815-120 \\ São Paulo, SP


